\title{
CAN RESTRICTIONS IN MEDITERRANEAN ARTISANAL FISHERIES BE BENEFICIAL FOR TARGET SPECIES?
}

\author{
Ivana BUŠELIĆ ${ }^{1}$, Nika STAGLIČIĆ ${ }^{1}$, Josep LLORET ${ }^{2}$, and Sanja MATIĆ-SKOKO ${ }^{\text {** }}$ \\ ${ }^{1}$ Institute of Oceanography and Fisheries, Split, Croatia \\ ${ }^{2}$ University of Girona, Faculty of Sciences, Campus Montilivi, Girona, Spain
}

\begin{abstract}
Bušelić I., Stagličić N., Lloret J., Matić-Skoko S. 2015. Can restrictions in Mediterranean artisanal fisheries be beneficial for target species? Acta Ichthyol. Piscat. 45 (1): 31-38.
\end{abstract}

Background. Marine protected areas (MPAs) with partial fishing restrictions are socially more acceptable, but their ecological effectiveness has largely not been assessed. The effects of establishing partial reserves on a target species, forkbeard, Phycis phycis (Linnaeus, 1766), were assessed in MPAs in the Mediterranean: Cap de Creus (Spain) and Lastovo (Croatia).

Materials and methods. In this study, we performed separate statistical analyses based on measurements of length and age for 381 forkbeard from Cap de Creus (2008- 2011) and 739 forkbeard from Lastovo Islands (2010-2012) as indicators of fishing effects on target fish populations.

Results. The establishment of partial reserves in both MPAs, with different regulations imposed on professional and recreational fishing has not proven successful in achieving benefits for a sedentary, relatively long-lived target species such as Phycis phycis. Results of multi-annual research indicate no significant difference in the abundance, mean size, or age of $P$. phycis between the fishing zones of different protection levels in either of the studied MPAs.

Conclusion. In order to achieve the desired benefits for coastal fisheries resources, we recommend that partial fishing reserves are supplemented with integrated networks of no-take zones.

Keywords: small-scale fisheries, reserve effect, marine protected area, Mediterranean Sea, partial protection, Phycis phycis, forkbeard

\section{INTRODUCTION}

The establishment of marine protected areas (MPAs), particularly those with no-take zones, is often viewed as a conflict between conservation and fishing. Partially protected areas (or partial reserves) that restrict some extractive uses, or where professional and recreational fishing are regulated in different ways, are often regarded as a balance between biodiversity conservation and socioeconomic viability (Sciberras et al. 2013). Although MPAs with partial protection seem to bring about advantages, such as enhanced density and biomass of fish, compared to areas with no restrictions, the strongest responses occur for the areas with total exclusion of fishing activities (Sciberras et al. 2013). In the Mediterranean, the comparison of the effects of total and partial restrictions to fishing on rocky-reef fish assemblages was undertaken by $\mathrm{Di}$ Franco et al. (2009). Nevertheless, there is a strong need for more studies to conclusively determine under which conditions partially protected areas constitute a valuable spatial management tool, particularly in areas where exclu- sion of all extractive activities is not a socio-economically and politically viable option. Shallow rocky habitats of Mediterranean coastal areas have been under human impact since ancient times (Sala 2004), due to high diversity of littoral benthic communities at small spatial scales. Fishery that developed in the coastal Mediterranean is, even nowadays, mainly characterized as artisanal (Papaconstantinou and Farrugio 2000, Battaglia et al. 2010). Artisanal fisheries are important from socio-cultural and economic point of view in the Mediterranean region (Colloca et al. 2004). It can be described as highly diverse in fishing gears and techniques, targeting a large variety of species in accordance with the season (Battaglia et al. 2010, Matić-Skoko et al. 2011b).

The scale of impacts the artisanal fisheries have on the resources are not as widely investigated and recognized as for industrial fishing (Hawkins and Roberts 2004). Generally, artisanal fisheries are considered more sustainable than large scale fisheries (Jacquet and Pauly 2008, Stobart et al. 2009), although by now a number of studies

\footnotetext{
* Correspondence: Prof. Dr. Sanja Matić-Skoko, Institut za oceanografiju i ribarstvo, Šetalište Ivana Meštrovića 63, P.O. Box. 500, 21000 Split, Croatia, phone: +38521408008, fax: +38521358650, e-mail: (SMS)sanja@izor.hr, (IB) buselic@izor.hr, (NS) nika@izor.hr, (JL) josep.lloret@udg.edu.
} 
have demonstrated that even artisanal fishing could profoundly affect the populations of target species and could have significant impacts on their reproductive potential (Hawkins and Roberts 2004, Lloret et al. 2012). Although restrictive regulation of fishing can induce the recovery of some coastal exploited fish populations (Roberts and Polunin 1991, Stobart et al. 2009), a question that remains unresolved is whether restricting artisanal fisheries is enough for a fish population to fully recover. We are exploring this issue in the presently reported study by assessing the frequency of catch, length, and age of the captured forkbeard, Phycis phycis (Linnaeus, 1766). Significant increase of the stated variables should be considered as beneficial.

Mediterranean MPAs have indeed provided options for excellent case studies since the artisanal fisheries have been partly restricted in the majority of them. Usually total restrictions were not imposed due to socio-economic reasons (Francour et al. 2001). In this paper we would like to compare the effects of restricted artisanal fisheries in two Mediterranean MPAs - Cap de Creus (Spain) and Lastovo (Croatia), where partially protected zones exist (i.e., areas where industrial fishing has been excluded while artisanal and sport/recreational fishing activities are restricted). Our focus species was the forkbeard, Phycis phycis. Specific type, quantity, characteristics, and temporal and spatial restrictions of fishing gear that can be used in the MPAs when performing artisanal, either commercial or subsistence, and recreational fishing are defined for both MPAs. The forkbeard, $P$. phycis, is a widely distributed and abundant species throughout Mediterranean rocky coastal communities (Cohen et al. 1990, Costa Abecasis et al. 2009) and highly targeted by artisanal fisheries (Farjallah et al. 2006, Matić-Skoko et al. 2011b, Lloret and Font 2013). However, in spite of its relatively broad geographic distribution and high economic value, the life history of the forkbeard is poorly known. It inhabits rocky bottoms and trawling grounds up to $370 \mathrm{~m}$ depth, although usually between 20 to $70 \mathrm{~m}$ with preference of larger individuals for sandy and muddy bottoms in deeper areas (Pallaoro and Jardas 2002). Age estimation revealed the maximum age of 18 years reported for Azorean archipelago (Costa Abecasis et al. 2009) implying that $P$. phycis is relatively slow growing and long lived species. Different population size structure and absence of larger individuals in the different geographic areas could be the result of their natural scarceness in the populations but also a direct consequence of a high fishing pressure or gear selectivity. As a predator active by night (Morato et al. 1999) the investigated gadiform is in particular very vulnerable to capture by trammel nets (Goñi et al. 2008). Therefore, $P$. phycis is a good candidate for evaluating the potential benefits of partial protection through restricting artisanal fisheries in the Mediterranean MPAs for target species. In this study, we measured the length and determined the age of individuals as presumptive indicators of fishing effects on target fish populations. At a population level, the removal of larger fish may be reflected in changes in mean length (age) or weight. Artisanal fishing particularly targets larger fish modifying the size structure and functioning of fish assemblages, with consequences for the reproductive potential of many stocks (Lloret et al. 2012). Therefore, size of organisms is a central factor to key ecological processes, and differences in size distributions may provide a relevant integration of the effects of fisheries on community structure (Shin et al. 2005).

\section{MATERIAL AND METHODS}

Study sites. The study was conducted at two differently regulated MPAs of the Mediterranean Sea (Cap de Creus in Spain and Lastovo Islands in Croatia), where artisanal fishing is of considerable importance to the local community. In both MPAs industrial fishing (trawling and purseseining) is completely prohibited while for artisanal fishing there are partial reserves where professional, subsistence and recreational fishing are regulated in different ways. The MPA of Cap de Creus is situated in the northwestern Mediterranean, partially comprising of the rocky coast of the eastern Pyrenees in Catalonia (Fig. 1). It was established in 1998 over the area of $30 \mathrm{~km}^{2}$ of sea divided in three different types of protection (Lloret and Riera 2008, Lloret et al. 2012): park zones, partial reserve zones, and integral reserve. In park zones and partial reserve artisanal fishing is allowed. Additionally, partial zones of Cap de Creus MPAs prohibit spear fishing. Integral reserve offers the highest protection with all forms of fishing forbidden. Artisanal fishing in Cap de Creus is carried out in small boats (usually less than $8 \mathrm{~m}$ in length), typically manned by a single fisherman and mainly operating on rocky bottoms of the park zones and partial reserves (Gómez et al. 2006). Fishing grounds within the waters of the MPA of Cap de Creus are exploited on regular to occasional basis by fishermen from four nearby coastal towns where all together in 2010 there were 12 boats registered in the fishermen's guilds. The forkbeard, Phycis phycis, is one of the principal species being caught by both professional and recreational (spear) fishers in the park zones of the MPA of Cape Creus, thus depicting the competition between spear and artisanal fishers for this species in these zones (Lloret and Font 2013). However, landings data on P. phycis are not available because they are mixed with landings data on another species of the same genus, such as the greater forkbeard Phycis blennoides (Brünnich, 1768).

The MPA of Lastovo Islands is situated in south-eastern part of the Adriatic Sea and it is the youngest Croatian MPA existing since 2006, covering an area of $143 \mathrm{~km}^{2}$ of the sea surface (Fig. 1). Its fishing protocol, declared in 2010, subdivided the MPA in 4 fishing zones which are to be successively used in pairs with a temporal rotation of three years. In the zones opened for fishing only 45 artisanal fishing permits are issued, imposing also restrictions on the type and quantity of allowed fishing gear compared to national legislation. Closed fishing zones prohibit any kind of artisanal com- 
mercial fishing activities, while fishing exclusively for subsistence and recreational purposes is allowed with much more severe restrictions regarding the type and quantity of fishing gear (e.g., only up to $200 \mathrm{~m}$ of few types of gillnets and hook and line tools), setting also a maximum allowable daily catch limit at $5 \mathrm{~kg}$.

Data collection. Onboard sampling was performed in collaboration with artisanal fishermen in the MPA of Cap de Creus in a period from January 2008 to December 2011 in the partial reserve and park zones. Established fishermen self-sampling programme is a result of training three artisanal fishers that were equipped and paid to provide information about their fisheries, including length-frequency measurements. Additional details of the sampling scheme are given in Lloret et al. (2012). In order to obtain comprehensive information on forkbeard, this study considered only trammel net catches, since these nets constitute the most frequently used fishing gear in the MPA of Cap de Creus (43\% of the total fishing sets) and are responsible for majority of caught forkbeard, Phycis phycis, according to fishermen self-sampling programme (98.7\%). The sampling depth ranged between 5 and $110 \mathrm{~m}$ (28.5 $\mathrm{m}$ on average), the mesh size of the inner panel ranged between $45 \mathrm{~mm}$ and $110 \mathrm{~mm}$, whereas the mesh size of the outer layer varied between 400 and $590 \mathrm{~mm}$. The size of all individuals was measured.

The monitoring of the state of fisheries resources in the MPA of Lastovo Islands started in 2010. It took four years after formal MPA proclamation, to develop and put in force the fishing protocol once the ranger service and logistics needed (e.g., speed boats) were all set. For last three years this investigation is aimed to assess the effectiveness of the proclaimed fisheries management in terms of ensuring the sustainability of fishing. The sampling always took place at the end of May or beginning of June, and lasted for approximately 10 days. Littoral fisheries resources were sampled by experimental trammel net fishing applying a structured hierarchical (five factors: year, protection, fishing zone, location, and site) experimental design. The sampling was conducted in collaboration with Public institution responsible for managing the MPA and local licensed artisanal fishermen. Four sampling locations, at a distance of approximately 10 to $15 \mathrm{~km}$, were surveyed each year in each of the fishing zones. At each location 2 sites were randomly chosen (separated by 2 to $5 \mathrm{~km}$ ) where fish were sampled using sets of trammel nets of the same construction and technical features which were operated in the same manner. Five, tied together, $1.8 \mathrm{~m}$ high and $100 \mathrm{~m}$ long 'poponica' trammel nets with inner layer mesh size of $28 \mathrm{~mm}$ and $150 \mathrm{~mm}$ mesh size of outer layers were set in the evening before sunset and retrieved in the morning after sunrise. In order to reduce any kind of variation that is not produced by different fishing regime, the trammel nets were always set at depths approximating $35 \mathrm{~m}$, and on similar bottoms. Catches in each of the $100 \mathrm{~m}$ trammel net sections were taken as replicates and the data extracted from this study were length and weight of every recorded specimen of forkbeard, in order to be compared with the data from Cap de Creus.

Ages of the specimens from both MPAs were estimated from the length frequencies using the von Bertalanffy equation obtained in Elafiti Islands (Adriatic Sea) (MatićSkoko et al. 2011a), which combined data for both sexes:

$$
L_{t}=64.3 \times\left(1-e^{(-0.200 \times(t+0.462))}\right)
$$

where:, where $L_{t}$ is the length of fish at age $t$.

Permits from relevant national governmental bodies were obtained prior to conducting the research in the MPAs of Cap de Creus and Lastovo Islands.

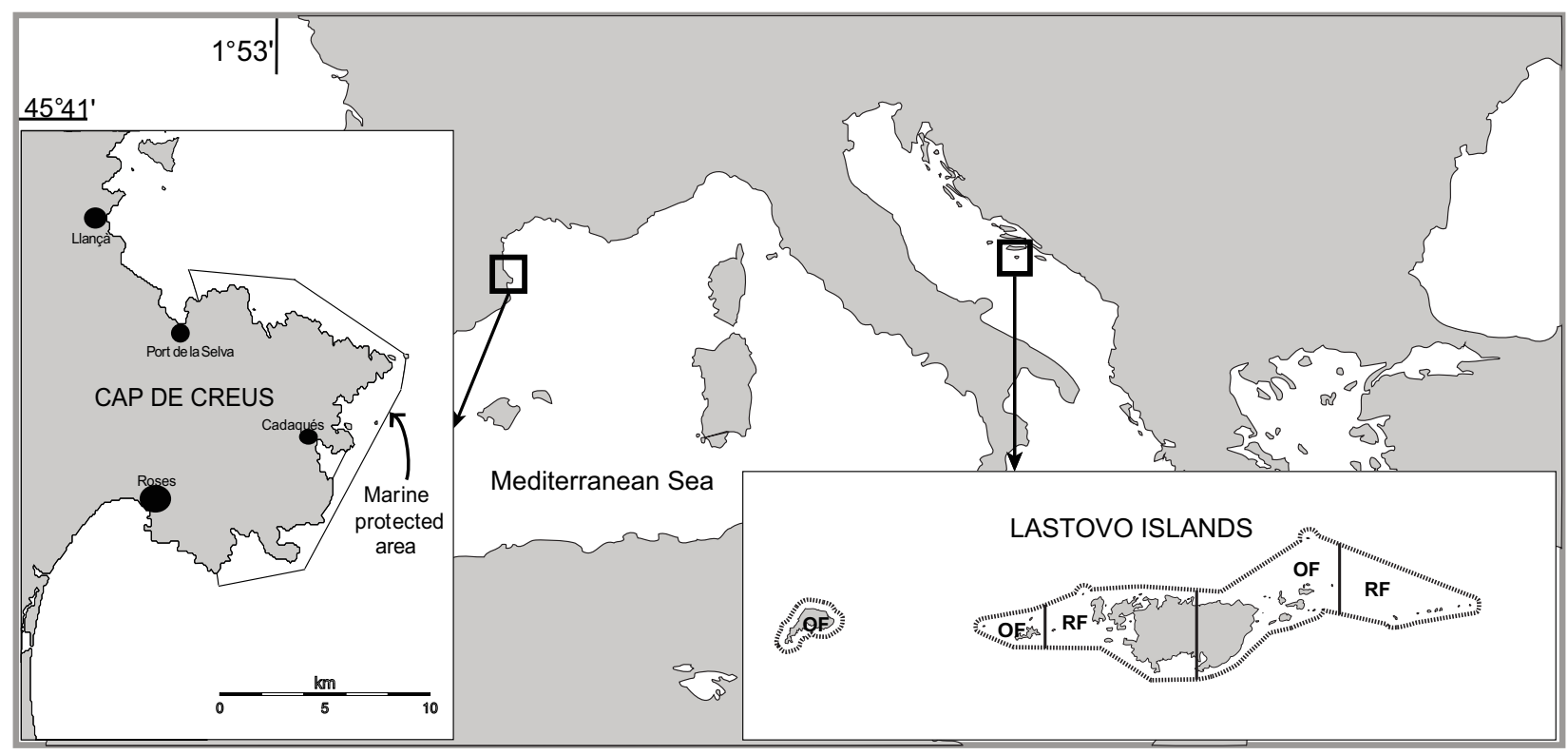

Fig. 1. Map of the Mediterranean Sea, showing enlarged investigated marine protected areas of Cap de Creus (Spain) and Lastovo Islands (Croatia); $\mathrm{P}=$ park zone, $\mathrm{PR}=$ partial reserve, $\mathrm{IR}=$ integral reserve, $\mathrm{RF}=$ restricted fishing, $\mathrm{OF}=$ open fishing 
Statistical analyses. Due to different sampling strategies applied in both investigated MPAs, it was not possible to compare directly differences between them. While the data from Cap de Creus provide an insight through fishermen's records (onboard sampling with the fishermen), the data from Lastovo Islands were from experimental trammel net fisheries following a structured hierarchical experimental design. The comparison is aimed mostly at the effectiveness of different types of protection illustrated through variation in length of forkbeard, Phycis phycis, caught in a period of 4 and 3 years, respectively.

Therefore, statistical analyses were performed separately for the two MPAs using the PRIMER 6 and Permanova + B20 package (Clarke and Gorley 2006, Anderson et al. 2008), where 'Year' was considered a random factor and orthogonal to fixed factor 'Protection' (for Cap de Creus). For data from Lastovo Islands, 'Year' was considered a random factor (3 levels), 'Protection' fixed (2 levels), 'Fishing zones' as a random factor (4 levels) nested into 'Protection', 'Area' as a random factor (2 levels) nested into 'Fishing zone' and 'Station' random factor (2 levels) nested into 'Area', for each replica (100 m of net). Permanova was used despite indices being univariate, because it avoids usual normality assumptions of ANOVA, and also permitting interpretation of interaction terms within random factors (Anderson 2001). The univariate tests used were based on Euclidean distance measure, and the $P$-values for the calculated $F$-statistics were obtained by permutation (999).

Across the years in any of the protection categories of the investigated MPAs, different number of forkbeard specimens was caught, thereby resulting in the study design being unbalanced at a replicate level. Ecological studies are often unbalanced due to uneven number of replicates taken/caught/observed under different conditions. Permanova analysis, in this regard also, provided the best approach as it has been specifically developed with such situations in mind and designed to cope well with unbalanced designs. Permanova tests were conducted with Type III sum of squares as recommended by Anderson et al. (2008), as this is the most conservative and widely accepted approach to managing unbalanced designs.

In order to test whether differences exist in the number of forkbeard caught under different protection levels of two MPAs across the years of investigation, chi-square tests of independence were performed in SPSS v. 19 statistical package. We were particularly interested in seeing whether the higher protection level in investigated MPAs has resulted in there being more large fish. Therefore, the distribution of forkbeard frequencies was tested taking into account the size of caught fish. All forkbeard specimens were classified in either a 'small' or 'large' size category depending on whether the specimens' length was smaller or larger than $1 / 2$ of the maximum attainable size reported (66 cm; Jardas 1996).

\section{RESULTS}

A total of 381 individuals of forkbeard, Phycis phycis, were measured from Cap de Creus between 2008 and 2011.
Number of specimens collected in each zone is given in Table 1. Data for Lastovo Islands covering the total of 739 forkbeard specimens, collected between 2010 and 2012, is also shown in Table 1. Large forkbeard ( $\geq 1 / 2$ max. attainable size) were generally less abundant in the catches than small ones (overall 146 large vs. 235 small in Cap de Creus; 167 large vs. 572 small in Lastovo Islands). No significant differences were determined in the frequency of large, adult forkbeard across protection levels or years of investigation in either of the two MPAs (Cap de Creus: $\chi^{2}=4.46 ; \mathrm{df}=3 ; P=0.22 ;$ Lastovo Islands: $\chi^{2}=0.24 ;$ $\mathrm{df}=2 ; P=0.89)$. In Lastovo Islands also smaller forkbeard were equally frequent in all the catches regardless of the protection level or year of investigation $\left(\chi^{2}=0.001\right.$; $\mathrm{df}=2$; $P=1.00)$, while in Cap de Creus significant differences exist $\left(\chi^{2}=19.11\right.$; df $\left.=3 ; P<0.001\right)$ largely owing to year 2010 when lower numbers of forkbeard were generally caught, but significantly less than expected for smaller sized forkbeards in the partial reserve zone.

Although mesh sizes between the two investigated MPAs differed greatly, the structure of the length distribution appeared to be very similar (Fig. 2). Mean length of the specimens from the MPA of Cap de Creus (31.35 \pm 8.42 ) is slightly higher than mean length of the specimens from the MPA of Lastovo Islands $(29.43 \pm 5.39)$, which could be explained by greater mesh size in the MPA of Cap de Creus, hence aimed at bigger sized part of the population. Even though the mesh size was greater in the MPA of Cap de Creus, recorded maximal length was in the same length class as in the MPA of Lastovo Islands.

Similar pattern in length distribution could also be seen in age distribution between two investigated sites (Fig. 3). Slightly higher mean age appeared in Cap de Creus $(3.08 \pm 1.43)$ compared to Lastovo Islands $(2.66 \pm$ 0.86 ), even though specimens belonging to age class of three years were dominantly more present in Lastovo Islands. Considering that the mesh size is larger and aimed at larger and older specimens, it is interesting that the youngest specimens (ages 1 and 2) were relatively more apparent in Cap de Creus than Lastovo Islands.

Results showed that there is no significant difference in mean length between park zones and partial reserve zones in the MPA of Cap de Creus (Table 2). Also, statistical analyses showed that there is no difference in length of the specimens between zones and years (Table 2) in the MPA of Lastovo Islands. In conclusion, besides effects of natural spatio-temporal variability, none other that could be attributed to protection were found to be significant at either of the investigated MPAs.

\section{DISCUSSION}

In general, our results provide evidence that partial reserves do not always provide the desired benefits for target fish populations, at least not clearly visible in a relatively short period of time and on selected fish species. Since there is no significant difference either in the frequency of catches or the mean length of catches of target species - the forkbeard, Phycis phycis-between 
park zones and partial reserve zones in the MPA of Cap de Creus (even considering that in the partial reserves there is no additional fishing pressure from spear fishing in comparison with the park zones), our results indicate that the system of partial reserves in Cap de Creus should be reconsidered, probably allowing the expansion of the non-take zone and/or introducing additional fishing restrictions in the partial reserves for artisanal fisheries.
The results of our study support the need to improve the management in partial reserves and quantitatively assess pressure of both professional (artisanal) and recreational fishing operating within and adjacent to MPAs (Di Franco et al. 2009, Sciberras et al. 2013, Tzanatos et al. 2013).

Also, since no difference in number, length, or weight of the forkbeard specimens caught between zones and years resulted as outcome of the three-year research con-

Length and weight for forkbeard, Phycis phycis, in marine protected areas (MPA)

Table 1 of Cap de Creus (Spain) and Lastovo Islands (Croatia)

\begin{tabular}{|c|c|c|c|c|c|}
\hline MPA & Status & Year & $N$ & Total length $[\mathrm{cm}]$ & $\begin{array}{c}\text { Total weight } \\
{[\mathrm{g}]}\end{array}$ \\
\hline \multirow{8}{*}{ 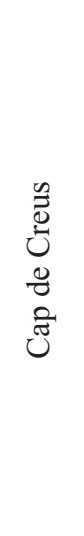 } & \multirow{4}{*}{ 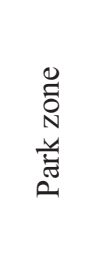 } & 2008 & 67 & $34.6 \pm 6.3$ & - \\
\hline & & 2009 & 40 & $33.2 \pm 8.0$ & 一 \\
\hline & & 2010 & 40 & $29.7 \pm 5.8$ & 一 \\
\hline & & 2011 & 49 & $24.5 \pm 7.2$ & - \\
\hline & \multirow{4}{*}{ 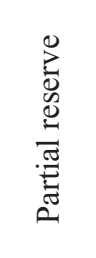 } & 2008 & 57 & $34.3 \pm 7.0$ & - \\
\hline & & 2009 & 57 & $31.8 \pm 7.3$ & - \\
\hline & & 2010 & 15 & $35.0 \pm 9.3$ & 一 \\
\hline & & 2011 & 56 & $26.2 \pm 8.3$ & - \\
\hline \multirow{6}{*}{ 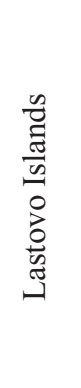 } & \multirow{3}{*}{ 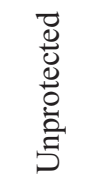 } & 2010 & 124 & $29.5 \pm 5.8$ & $311.3 \pm 216.7$ \\
\hline & & 2011 & 99 & $29.4 \pm 5.6$ & $300.9 \pm 229.9$ \\
\hline & & 2012 & 97 & $27.9 \pm 4.3$ & $257.3 \pm 139.6$ \\
\hline & \multirow{3}{*}{$\begin{array}{l}\overrightarrow{0} \\
0 \\
0 \\
0 \\
0\end{array}$} & 2010 & 160 & $30.4 \pm 6.0$ & $329.1 \pm 210.3$ \\
\hline & & 2011 & 135 & $30.2 \pm 5.0$ & $326.1 \pm 179.4$ \\
\hline & & 2012 & 124 & $29.1 \pm 4.9$ & $283.9 \pm 160.6$ \\
\hline
\end{tabular}

The weight for specimens from MPA Cap de Creus was not measured; Length and weight values are mean \pm standard deviation; $N=$ number of fish. Total length of caught fish was measured to the nearest $0.1 \mathrm{~cm}$ and total body weight to the nearest $0.1 \mathrm{~g}$.

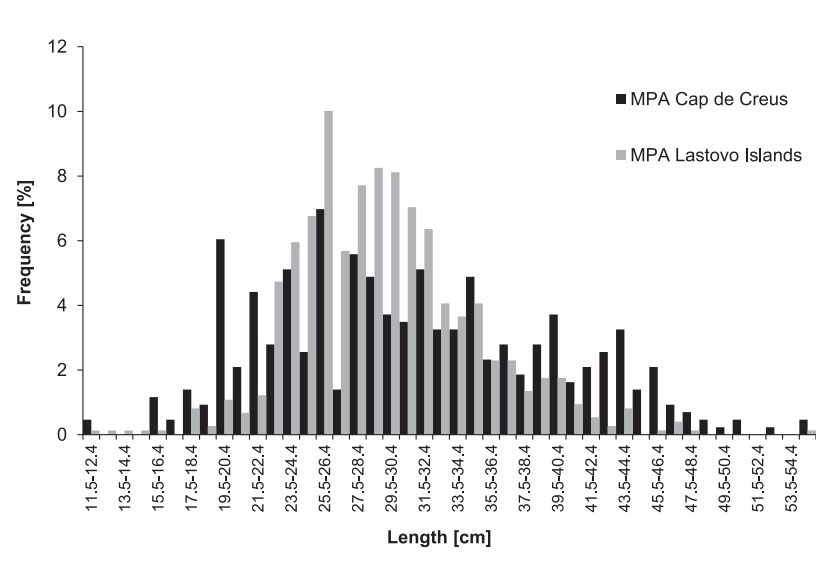

Fig. 2. Length-frequency distributions of forkbeard, Phycis phycis, in marine protected areas (MPA) of Cap de Creus (Spain) and Lastovo Islands (Croatia)

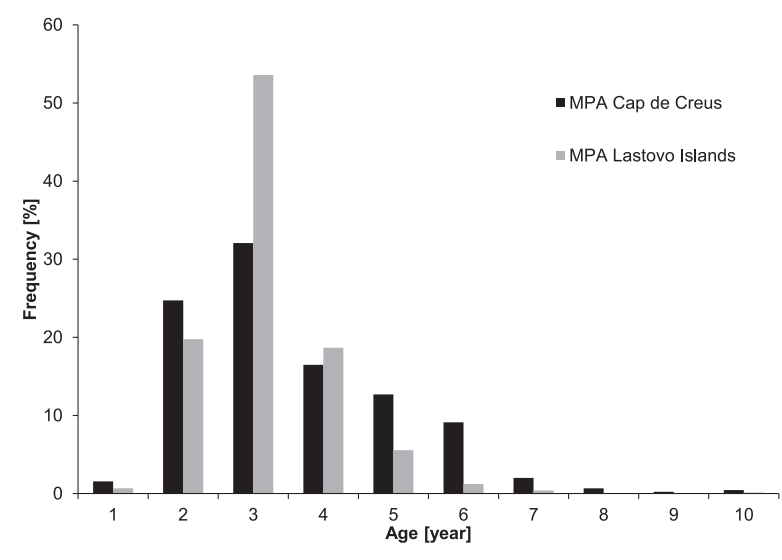

ig. 3. Age distribution among two investigated marine protected areas of Cap de Creus (Spain) and Lastovo Islands (Croatia) 
ducted in the MPA of Lastovo Islands, the park management should consider finding a more effective mode of fishing regulation. The forkbeard, Phycis phycis, is a relatively long-lived species, so it is possible that the investigated period was too short to detect effects of protection. Rotational type of fishing regulation within the MPA of Lastovo Islands represents one of the few examples worldwide, noted in literature before only on island Oahu, Hawaii in 1978 (Williams et al. 2006). Long term surveillance (over 2 decades) revealed this type of management was not effective in terms of resource preservation and sustainable fishing. The only part of the Hawaiian MPA that showed progress and positive trend in resources was the one proclaimed a no-take zone in 1988. Nevertheless, from sociological point of view it was advised to maintain fishing regulation within the MPA of Lastovo Islands at least until 2013, when first rotation occurred. What is needed now, would be to continue monitoring the state of resources and check with local population and fishermen whether they are opened for new suggestions and protection alterations.

More than a several examples confirmed that it takes five years or more to achieve significant effects of protection, namely in no-take zones, on coastal resources (Guidetti et al. 2010, Aburto-Oropeza et al. 2011). GarcíaRubies et al. (2013) confirm that fish populations may require decadal time scales to recover from exploitation, both in terms of total abundance and total biomass and that rates of recovery differ between species. However, even with total exclusion of fishing effort, depleted stocks sometimes show little or no recovery over a long time period. Takashina and Mougi (2014) found that MPAs can have either a positive effect or almost no effect on the recovery of depleted fishing stocks, depending on the fish migration patterns and the fishing policies. MPAs also reinforce ecological resilience, particularly for migratory species. In contrast to previous reports, their results show that MPAs have small or sometimes negative effects on the recovery of sedentary species. Also, unsuitable MPA planning might result in low effectiveness or even deterioration of the existing condition.

The benefits of protection for sedentary, relatively long lived target species such as forkbeard, Phycis phycis, in MPAs of Cap de Creus and Lastovo Islands are likely impaired by artisanal fishing that takes place throughout the investigated zones. Furthermore, recreational fishing is freely allowed in both of the investigated MPAs and park managers should consider additional limitations. In a French MPA, Cadiou et al. (2009) demonstrated that progressively banning recreational fishing has also made restrictions on commercial fishing more acceptable in social terms. For any MPA to be effective and supported by the local community compatibility between conservation of the environment and the maintenance of commercially viable and sustainable fishing, within the context of the consultation process, is necessary. Further on, when studies suggest that MPA may not positively influence the fish productivity or recovery, extenuating factors such as insufficient time since MPA creation, poor or lack of enforcement, inadequate design, and poorly defined management objectives are generally blamed rather than failure of the MPA concept (Grüss et al. 2014). However, we often forget that not all species are equally vulnerable to fishing effort, nor all species recover with the same speed. The vision should also promote the recovery of ecosystems and rebuilding of marine commercial stocks and predator species.

Permanova results for length of forkbeard, Phycis phycis, caught in marine protected areas

Table 2 of Cap de Creus (Spain) and Lastovo Islands (Croatia)

\begin{tabular}{|c|c|c|c|c|c|c|c|}
\hline MPA & Source & $\mathrm{df}$ & SS & MS & Pseudo-F & $\mathrm{P}_{\text {(perm) }}$ & Unique perms \\
\hline \multirow{4}{*}{ 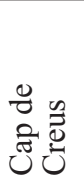 } & $\mathrm{Y}$ & 3 & 5149.10 & 1716.40 & 32.727 & $0.001^{P}$ & 999 \\
\hline & $\mathrm{S}$ & 1 & 132.47 & 132.47 & 2.526 & 0.112 & 994 \\
\hline & $\mathrm{Y} \times \mathrm{S}$ & 3 & 403.36 & 134.49 & 2.564 & 0.059 & 998 \\
\hline & Residual & 373 & 19562 & 52.45 & & & \\
\hline \multirow{10}{*}{ 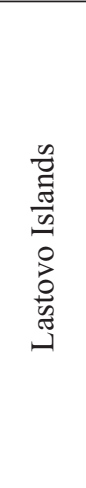 } & $\mathrm{Y}$ & 2 & 121.41 & 60.71 & 2.645 & 0.124 & 999 \\
\hline & $\mathrm{S}$ & 1 & 168.04 & 168.04 & 0.960 & 0.368 & 801 \\
\hline & $\mathrm{Z}(\mathrm{S})$ & 2 & 29.27 & 14.64 & 0.083 & 0.911 & 818 \\
\hline & $\mathrm{Y} \times \mathrm{S}$ & 2 & 8.02 & 4.01 & 0.175 & 0.843 & 998 \\
\hline & $\mathrm{A}(\mathrm{Z}(\mathrm{S}))$ & 4 & 707.76 & 176.94 & 11.677 & $0.001^{P}$ & 999 \\
\hline & $\mathrm{Y} \times \mathrm{Z}(\mathrm{S})$ & 4 & 124.23 & 31.06 & 1.358 & 0.330 & 999 \\
\hline & $\mathrm{S}(\mathrm{A}(\mathrm{Z}(\mathrm{S})))$ & 8 & 115.12 & 14.39 & 0.522 & 0.844 & 999 \\
\hline & $\mathrm{Y} \times \mathrm{A}(\mathrm{Z}(\mathrm{S}))$ & 8 & 182.24 & 22.78 & 0.672 & 0.688 & 999 \\
\hline & $\mathrm{Y} \times \mathrm{S}(\mathrm{A}(\mathrm{Z}(\mathrm{S})))$ & 16 & 551.47 & 34.47 & 1.251 & 0.238 & 996 \\
\hline & Residual & 691 & 19040 & 27.55 & & & \\
\hline
\end{tabular}

$\mathrm{Y}=$ year, $\mathrm{S}=$ protection status, $\mathrm{Z}=$ zone, $\mathrm{A}=$ area, $\mathrm{S}=$ station $^{P}=P<0.01$. 
A growing number of scientific evidence suggests numerous advantages of establishing networks of no-take zones over partially protected areas (Lester and Halpern 2008), due to its greater ecological as well as fisheries benefits. In the Mediterranean, no-take zones represent less than $0.1 \%$ of the surface and rarely exceed $10 \%$ of the total size of the MPAs (Abdulla et al. 2008, Font et al. 2012). Nevertheless, such redirection requires balanced ecological, socio-economical, and political aspects, which in highly populated Mediterranean coastal area imply participatory approach including all stakeholders.

Overall, our results indicate the necessity of favouring the establishment or enlargement of no-take areas and rethinking the role of partially protected areas. Although these partial reserves can be a valuable spatial management tool in areas such as Cap de Creus and Lastovo where exclusion of all extractive activities is a difficult socio-economically and politically viable option, they will probably not become an effective option for conservation of fish stocks until the adequate additional artisanal and recreational fishing restrictions are implemented.

\section{ACKNOWLEDGEMENTS}

The sampling was undertaken by the following bodies, and we gratefully acknowledge their support and input into this study: the MPA of Cap de Creus, the MPA of Lastovo Islands, the local fishermen, the INTERREG IIIc project MEDPAN, the Spanish Ministry of Science and Innovation (Project Ref. CTM2006-13964-C03-01), the Croatian Ministry of Science (Project Ref. 001-00130770844), the Croatian Ministry of Environmental and Nature Protection, the Association for Nature, Environment and Sustainable Development "Sunce" (through MedPAN South project). Josep Lloret benefited from a Ramón y Cajal contract of the Spanish Ministry of Economy and Competitiveness.

\section{REFERENCES}

Abdulla A., Gomei M., Maison E., Piante C. 2008. Status of Marine Protected Areas in the Mediterranean Sea. IUCN, Malaga and WWF, France.

Aburto-Oropeza O., Erisman B., Galland G.R., MascareñasOsorio I., Sala E., Ezcurra E. 2011. Large recovery of fish biomass in a no-take marine reserve. PloS ONE 6 (8): e23601. DOI: 10.1371/journal.pone.0023601

Anderson M.J. 2001 A new method for non-parametric multivariate analysis of variance. Austral Ecology 26 (1): 32-46. DOI: 10.1111/j.1442-9993.2001.01070.pp.x

Anderson M.J., Gorley R.N., Clarke K.R. 2008. PERMANOVA for PRIMER: Guide to Software and Statistical Methods. PRIMER-E, Plymouth, UK.

Battaglia P., Romeo T., Consoli P., Scotti G., Andaloro F. 2010. Characterization of the artisanal fishery and its socioeconomic aspects in the central Mediterranean Sea (Aeolian Islands, Italy). Fisheries Research 102 (1-2): 87-97. DOI: 10.1016/j.fishres.2009.10.013

Cadiou G., Boudouresque C. F., Bonhomme P., Le Diréach L. 2009. The management of artisanal fishing within the
Marine Protected Area of the Port-Cros National Park (northwest Mediterranean Sea): a success story? ICES Journal of Marine Science 66 (1): 41-49.

DOI: $10.1093 /$ icesjms/fsn 188

Clarke K.R., Gorley R.N. 2006. PRIMER v6: UserManual/Tutorial. PRIMER-E, Plymouth, UK.

Cohen D., Inada T., Iwamoto T., Scialabba N. 1990. Gadiform fishes of the world (Order Gadiformes). FAO Species Catalogue. FAO Fisheries Synopsis No. 125. Vol. 10. FAO, Rome.

Colloca F., Crespi V., Cerasi S., Coppola S.R. 2004. Structure and evolution of the artisanal fishery in southern Italian coastal area. Fisheries Research 69 (3): 359-369. DOI: 10.1016/j.fishres.2004.06.014

Costa Abecasis A.R., Canha A., Reis D., Pinho M.R., GilPereira J. 2009. Age and growth of the forkbeard Phycis phycis (Gadidae) from the Azorean archipelago, North Atlantic. Journal of Marine Biology Association of the United Kingdom 89 (3): 629-633.

DOI: $10.1017 /$ S0025315409002598

Di Franco A., Bussotti S., Navone A., Panzalis P., Guidetti P. 2009. Evaluating effects of total and partial restrictions to fishing on Mediterranean rocky-reef fish assemblages. Marine Ecology Progres Series 387: 275-285. DOI: $10.3354 /$ meps08051

Farjallah S., Slimane B.B., Blel H., Amor N., Said K. 2006. Anisakid parasites of two forkbeards (Phycis blennoides and Phycis phycis) from the eastern Mediterranean coasts in Tunisia. Parasitology Research 100 (1): 11-17. DOI: $10.1007 / \mathrm{s} 00436-006-0227-7$

Font T., Lloret J., Piante C. 2012. Recreational fishing within Marine Protected Areas in the Mediterranean. MedPAN North Project. WWF France.

Francour P., Harmelin J.-G., Pollard D., Sartoretto S. 2001. A review of marine protected areas in the northwestern Mediterranean region: sitting, usage, zonation and management. Aquatic Conservation: Marine and Freshwater Ecosystems 11 (3): 155-188.

DOI: $10.1002 /$ aqc. 442

García-Rubies A., Hereu B., Zabala M. 2013. Long-term recovery patterns and limited spillover of large predatory fish in a Mediterranean MPA. PLoS ONE 8: e73922. DOI: 10.1371/journal.pone.0073922

Gómez S., Lloret J., Demestre M., Riera V. 2006. The decline of the artisanal fisheries in Mediterranean coastal areas: the case of Cap de Creus (Cape Creus). Coastal Management 34 (2): 217-232.

DOI: $10.1080 / 08920750500531389$

Goñi R., Adlerstein S., Alvarez-Berastegui D., Forcada A., Reñones O., Criquet G., Polti S., Cadiou G., Valle C., Lenfant P., Bonhomme P., Pérez-Ruzafa A., SánchezLizaso J.L., García-Charton J.A., Bernard G., Stelzenmüller V., Planes S. 2008. Spillover from six western Mediterranean marine protected areas: Evidence from artisanal fisheries. Marine Ecology Progress Series 366: 159-174. DOI: $10.3354 /$ meps07532

Grüss A., Robinson J., Heppell S.S., Heppell S.A., Semmens B.X. 2014. Conservation and fisheries effects of spawning aggregation marine protected areas: What we know, where we 
should go, and what we need to get there. ICES Journal of Marine Science 71 (7): 1515-1534.

DOI: $10.1093 /$ icesjms/fsu038

Guidetti P., Bussotti S., Pizzolante F., Ciccolella A. 2010. Assessing the potential of an artisanal fishing co-management in the Marine Protected Area of Torre Guaceto (southern Adriatic Sea, SE Italy). Fisheries Research 101 (3): 180-187. DOI: 10.1016/j.fishres.2009.10.006

Hawkins J.P., Roberts C.M. 2004. Effects of artisanal fishing on Caribbean coral reefs. Conservation Biology 18 (1): 215-226. DOI: $10.1111 / \mathrm{j} .1523-1739.2004 .00328 . x$

Jacquet J., Pauly D. 2008. Funding priorities: big barriers to small-scale fisheries. Conservation Biology 22 (4): 832-835. DOI: $10.1111 /$ j.1523-1739.2008.00978.x

Jardas I. 1996. Jadranska ihtiofauna. [Adriatic ichthyofauna.] Školska knjiga, Zagreb, Croatia. [In Croatian.]

Lester S.E., Halpern B.S. 2008. Biological responses in marine no-take reserves versus partially protected areas. Marine Ecology Progress Series 367: 49-56. DOI: $10.3354 / \mathrm{meps} 07599$

Lloret J., Font T. 2013. A comparative analysis between recreational and artisanal fisheries in a Mediterranean coastal area. Fisheries Management and Ecology 20 (2-3): 148-160. DOI: 10.1111/j.1365-2400.2012.00868.x

Lloret J., Muñoz M., Casadevall M. 2012. Threats posed by artisanal fisheries to the reproduction of coastal fish species in a Mediterranean marine protected area. Estuarine Coastal and Shelf Science 113: 133-140. DOI: 10.1016/j.ecss.2012.07.015

Lloret J., Riera V. 2008. Evolution of a Mediterranean coastal zone: human impacts on the marine environment of Cape Creus. Environmental Management 42 (6): 977-988. DOI: $10.1007 / \mathrm{s} 00267-008-9196-1$

Matić-Skoko S., Ferri J., Škeljo F., Bartulović V., Glavić K., Glamuzina B. 2011a. Age, growth and validation of otolith morphometrics as predictors of age in the forkbeard, Phycis phycis (Gadidae). Fisheries Research 112 (1-2): 52-58. DOI: 10.1016/j.fishres.2011.08.010

Matić-Skoko S., Stagličić N., Pallaoro A., Kraljević M., Dulčić J., Tutman P., Dragičević B. 2011b. Effectiveness of conventional management in Mediterranean type artisanal fisheries. Estuarine Coastal and Shelf Science 91 (2): 314-324. DOI: 10.1016/j.ecss.2010.10.029

Morato T., Solà E., Grós M.P., Menezes G. 1999. Diets of forkbeard (Phycis phycis) and conger eel (Conger conger) off the Azores during spring of 1996 and 1997. Arquipélago: Life and Marine Sciences 17A: 51-64.
Pallaoro A., Jardas I. 2002. Remarks on horizontal and vertical distribution of family Gadidae, Lotidae and Phycidae representatives in the eastern Adriatic. Acta Adriatica 43: 3-15.

Papaconstantinou C., Farrugio H. 2000. Fisheries in the Mediterranean. Mediterranean Marine Science 1 (1): 5-18. DOI: $10.12681 / \mathrm{mms} .2$

Roberts C.M., Polunin N.V.C. 1991. Are marine reserves effective in management of reef fisheries? Review of Fish Biology and Fisheries 1 (1): 65-91.

DOI: $10.1007 / \mathrm{BF} 00042662$

Sala E. 2004. The past and present topology and structure of the Mediterranean subtidal rocky-shore food webs. Ecosystems 7 (7): 333-340.

DOI: $10.1007 / \mathrm{s} 10021-003-0241-\mathrm{x}$

Sciberras M., Jenkins S.R., Mant R., Kaiser M.J., Hawkins S.J., Pullin A.S. 2013. Evaluating the relative conservation value of fully and partially protected marine areas. Fish and Fisheries 16 (1): 58-77.

DOI: $10.1111 /$ faf.12044

Shin Y-J., Rochet M-J., Jennings S., Field J.G., Gislason H. 2005. Using size-based indicators to evaluate the ecosystem effects of fishing. ICES Journal of Marine Science 62 (3): 384-396. DOI: 10.1016/j.icesjms.2005.01.004

Stobart B., Warwick R., Gonzalez C., Mallol S., Diaz D., Reñones O. 2009. Long-term and spillover effects of a marine protected area on an exploited fish community. Marine Ecology Progress Series 384: 47-60.

DOI: $10.3354 / \mathrm{meps} 08007$

Takashina N., Mougi A. 2014. Effects of marine protected areas on overfished fishing stocks with multiple stable states. Journal of Theoretical Biology 341: 64-70.

DOI: $10.1016 /$ j.jtbi.2013.09.027

Tzanatos E., Castro J., Forcada A., Matić-Skoko S., Gaspar M., Koutsikopoulos C. 2013. A Métier-Sustainability-Index $\left(\mathrm{MSI}_{25}\right)$ to evaluate fisheries components: Assessment of cases from data-poor fisheries from southern Europe. ICES Journal of Marine Science 70 (1): 78-98.

DOI: $10.1093 /$ icesjms/fss161

Williams I.D., Walsh W.J., Miyasaka A., Friedlander A.M. 2006. Effects of rotational closure on coral reef fishes in WaikikiDiamond Head Fishery Management Area, Oahu, Hawaii. Marine Ecology Progress Series 310: 139-149.

DOI: $10.3354 / \operatorname{meps} 310139$

Received: 17 July 2014

Accepted: 9 February 2015

Published electronically: 31 March 2015 